\title{
FORMAS DE CULMINACIÓN DEL PROCESO PENAL POR FALTA. UNA PROPUESTA DE INTEGRACIÓN NORMATIVA
}

\author{
MARIO LOHONEL ABANTO QUEVEDO*
}

\section{Resumen}

Ante la insuficiente regulación del proceso penal por falta en el Código Procesal Penal de 2004, se propone integrar los vacíos normativos a través de la actividad interpretativa del Juez. Esta opción se aplica para los casos de culminación de tal clase de proceso penal y se expone cada una en este ensayo.

Palabras clave: Integración - Interpretación - Querellante particular Conciliación - Desistimiento - Abandono - Exención de pena - Reserva de fallo condenatorio - Prescripción.

\begin{abstract}
Given the inadequate regulation of criminal proceedings for want of the Code of Criminal Procedure, 2004, this paper intends to integrate the law through the judge's interpretive activity. This technique is applied to the different ways it can end this kind of criminal trial and are exposed in this essay.
\end{abstract}

Key words: Integration - Interpretation - Private accuser - Conciliation Retirement - Abandonment - Exemption of penalty - Reserve judgment of conviction - Prescription.

\section{Sumario}

1.- Introducción. 2.- Desistimiento expreso. 3.- Desistimiento tácito. 4.Conciliación. 4.1.- Conciliación pura. 4.2.- Conciliación civil o acuerdo reparatorio. 4.3.- Conciliación mixta. 5.- Sentencia que se pronuncia por la responsabilidad penal. 5.1.- Sentencia condenatoria. 5.2.- Sentencia con reserva de fallo condenatorio. 5.3.- Sentencia de exención de pena. 6.Sentencia que se pronuncia por la irresponsabilidad penal. 7.- Abandono del proceso. 8.- Prescripción de la acción penal. 9.- Conclusiones. 10.- Lista de referencias.

\footnotetext{
* Juez Titular del Cuarto Juzgado de Paz Letrado de la Corte Superior de Justicia de Cajamarca - Poder Judicial del Perú.
} 
Mario Lohonel Abanto Quevedo - Formas de culminación del Proceso Penal por falta.

Una propuesta de integración normativa

\section{INTRODUCCIÓN}

El proceso penal por falta está regulado expresamente en apenas seis artículos (arts. 482 al 487) del Código Procesal Penal (CPP 2004), que son los correspondientes a la Sección VII del Libro Quinto, dedicada a los procesos especiales. Sin embargo, como veremos en este ensayo, en varias ocasiones es necesario realizar una interpretación constitucional, sistemática e integradora ${ }^{1}$, para completar la regulación del proceso penal por falta. De ese modo, acudiremos a la Sección IV (proceso por delito de ejercicio privado de la acción penal) del mismo Libro Quinto, pero también a algunas disposiciones específicas de los Libros Tercero (el proceso común) y Cuarto (la impugnación).

El objetivo de este ensayo es ocuparnos de las diversas formas de culminación del proceso penal por falta, realizando la interpretación mencionada, proponiendo en cada caso la oportunidad, características y consecuencias de estas distintas opciones de término del proceso penal. Sostenemos que interpretar para integrar las disposiciones procesales es concreción del deber constitucional y legal de los jueces de no dejar de impartir justicia por vacío o deficiencia de la ley, establecido en el art. 139.8 de la Constitución Política de 1993 (CP 1993) y en el segundo párrafo del art. III del Título Preliminar del Texto Único Ordenado del Código Procesal Civil (TP TUO CPC 1993), respectivamente.

\section{DESISTIMIENTO EXPRESO}

Siendo el proceso penal por falta uno "sustancialmente acelerado y con predominio de la concentración procesal" (SAN MARTín CASTRO 2003, 1263) en el que no interviene el Ministerio Público y la figura del Juez es preponderante en su dirección, este debe intervenir procurando legitimar su participación. Para esto debe desterrar la tendencia inquisitiva y optimizar el principio acusatorio ${ }^{2}$.

\footnotetext{
1 Sentencia del Tribunal Constitucional (STC) en el Exp. 0030-2005-AI/TC, fundamento jurídico (FJ) 39: "La interpretación es una función inherente a la labor de todo operador del Derecho; es decir, inherente a la labor del operador de las normas jurídicas".

2 La constitucionalidad del proceso penal por falta ha estado y está en entredicho incluso antes de la vigencia del CPP 2004. SAN MARTín CASTRO $(2003,1264)$ se unía a este cuestionamiento al sostener que "el principio acusatorio brilla por su ausencia y, por tanto, la constitucionalidad del procedimiento se ve discutida por vulneración de las garantías genéricas del debido proceso y del derecho de defensa". Al no haber cambiado las esenciales características del proceso penal por falta, bajo las reglas del CPP 2004, el Juez debe aplicar las disposiciones procesales tendiendo a la igualdad de armas y a la prevalencia de las garantías del debido proceso. Para Gálvez Villegas, Rabanal Palacios y CASTRO TRIGOSO $(2009,906)$ “posibilitar un juicio y una condena por faltas sin la intervención del fiscal (...), viola el principio acusatorio".
} 
Mario Lohonel Abanto Quevedo - Formas de culminación del Proceso Penal por falta.

Una propuesta de integración normativa

Según este esquema, le corresponde al Juez exigir el cumplimiento de las responsabilidades de los actores procesales. Ya que la persona agraviada por un caso de falta interviene en el proceso en condición de querellante particular ${ }^{3}$ (no como actor civil), se le aplican las previsiones que a esta calidad de actor le ha asignado el derecho procesal. Entre estas previsiones se encuentra el desistimiento de la acción penal, cuya interposición facultativa también determina del mismo modo, una de las formas de su extinción.

El desistimiento de la acción penal privada por un caso de falta es voluntario ${ }^{4}$, "equivale a conceder a la víctima poder dispositivo sobre el objeto del proceso penal, sobre la persecución" (SAN MARTín CASTRO 2003, 1262). Como tal, puede presentarse antes de realizar la audiencia única del caso o durante ésta. En la etapa preliminar, esto es, durante la investigación policial ${ }^{5}$, puede presentarse el desistimiento, evitando que el caso llegue a conocimiento del Juez. Esto puede hacerse personalmente al brindar la declaración policial e incluso por escrito, antes o después de dicha diligencia (por ejemplo, presentando una transacción notarial).

Ya si el caso -denunciado correctamente ${ }^{6}$ en los términos del art. 108 del CPP 2004 e investigado diligentemente- ha sido enviado con informe policial al Juzgado de Paz Letrado o al Juzgado de Paz, estando listo para su calificación y la emisión del auto de enjuiciamiento, aún es posible presentar el desistimiento. El art. 487 del CPP 2004 establece que "En cualquier estado de la causa, el agraviado o querellante puede desistirse o transigir, con lo que se dará por fenecido el proceso." En concordancia con la citada disposición procesal, el art. 78.3 del Código Penal (CP 1991), prescribe: "En los casos que sólo proceda la acción privada, ésta se extingue, además de las establecidas en el numeral 1, por desistimiento o transacción". Finalmente, el sustento legal se cierra con la disposición especial del art. 110 del CPP 2004.

Si se produjese el desistimiento expreso de la acción penal privada -por escrito o verbalmente- frente al Juez y su Secretario Judicial, antes o durante la audiencia, se debe acceder a dicho pedido después de verificar que el

3 CPP 2004, art. 483.1: La persona ofendida por una falta puede denunciar su comisión ante la Policía o dirigirse directamente al Juez comunicando el hecho, constituyéndose en querellante particular.

4 A favor del desistimiento, pero con reservas en los casos de violencia intrafamiliar, en los que la víctima puede ser forzada a desistirse de su denuncia, MACHUCA $(2011,90)$.

5 La Policía Nacional del Perú, a través del personal de la Sección de Investigación de Delitos y Faltas, investiga los casos de falta. El sustento legal se halla en el art. 166 de la CP 1993, los arts. 3 y 7.2 de la Ley n. ${ }^{\circ} 27238$, el art. 440.6 del CP 1991 y el art. 483.2 del CPP 2004.

6 Sánchez $(2009,403)$ es claro al sugerir que "si no se satisfacen los requisitos indicados, el juez dictará auto de archivo de lo actuado". 
Mario Lohonel Abanto Quevedo - Formas de culminación del Proceso Penal por falta.

Una propuesta de integración normativa

querellante particular no actúa compelido por ningún factor externo ilícito y que comprende el alcance de esta manifestación de voluntad ${ }^{7}$. Puede oponerse a la consideración de este último efecto la literalidad de la disposición procesal, que se refiere a quien "se ha desistido de una querella" al no ser el proceso penal por falta, en estricto, uno por querella. Sin embargo, nuevamente creo necesario indicar que el incipiente estado regulatorio del proceso penal por falta obliga a la integración normativa a través de la interpretación sistemática ${ }^{8}$. Esta posibilidad está habilitada expresamente para el caso por el art. $483.1 \mathrm{del} \mathrm{CPP} \mathrm{2004.} \mathrm{De} \mathrm{ese} \mathrm{modo,} \mathrm{todas} \mathrm{las} \mathrm{disposiciones} \mathrm{procesales} \mathrm{que}$ reconocen derechos y facultades del querellante particular, pero que también le fijan límites y consecuencias preclusivas a sus decisiones, son aplicables en tanto sean "adecuadas a la brevedad y simpleza del proceso por faltas" (art. 484. 4 in fine del CPP 2004).

Finalmente, de acuerdo al art. 497.5 del CPP 2004, no procede la imposición de costas en los procesos por faltas, siendo esta una excepción a la regla establecida previamente en el art. 13.2 del mismo Código.

\section{DESISTIMIENTO TÁCITO}

El desistimiento tácito sólo es posible intraproceso. Se requiere de la previa emisión del auto de enjuiciamiento, en el que se califica el hecho denunciado, se considera la pretensión penal y la justificación de la pretensión resarcitoria opuestas por el querellante particular, se señala fecha para realizar la audiencia única y se requiere a las partes asistir con sus abogados defensores y con los elementos y medios de prueba que pretendan hacer valer. Es muy importante contar con las constancias de notificación, hechas a ambas partes oportunamente, esto es, antes del momento señalado para realizar la audiencia9.

7 CPP 2004, art. 464.3: El que se ha desistido de una querella o la ha abandonado, no podrá intentarla de nuevo.

8 La naturaleza, derechos, facultades y sanciones procesales que son propias del querellante particular se encuentran desarrollados en el propio CPP 2004, pues a él se hace imperativo recurrir en aplicación de la interpretación sistemática de las disposiciones legales de carácter procesal. Ergo, el art. 483 del CPP 2004 es una disposición legal remisiva respecto al Capítulo III (arts. 107 a 110) del Título IV de la Sección IV del Libro Primero del CPP 2004, pero también de la Sección IV (arts. 459 al 467) del Libro Quinto del mismo Código, referido a los Procesos Especiales (querella). Basta cotejar la referencia que entre sí realizan los artículos citados, en procura de unidad y coherencia sistemática, para advertir que el objetivo de la concordancia es eliminar el riesgo de antinomias o vacíos legales.

9 Si ambas partes han señalado domicilio procesal en la etapa de investigación policial o lo han hecho cuando el informe policial ya ha sido enviado al Juzgado de Paz Letrado, deberá ordenarse realizar la notificación solo en el domicilio procesal señalado. Esto se hace así en observancia de los incisos 3 y 4 del art. 127 del CPP 2004. 
Mario Lohonel Abanto Quevedo - Formas de culminación del Proceso Penal por falta.

Una propuesta de integración normativa

Al llegar el día y hora exacta señalados para la audiencia única, si no asisten ambas partes, obviamente la audiencia no se realiza. Tampoco si es que sólo asiste el querellante particular. En el primer escenario, sin embargo, el Juez de Paz Letrado no debe reprogramar la audiencia de oficio, ya que el proceso penal por falta inició por impulso del querellante particular (ciudadano, ciudadana o representante de la colectividad que resulta agraviado o víctima de una falta) y bajo el mismo principio $^{10}$ debe continuar o no.

Partiendo de la intervención del querellante particular en los procesos por querella (similares al proceso penal por falta, desde su origen a instancia de parte, no intervención de fiscal, deber de carga de la prueba, posibilidad de desistimiento, transacción y conciliación, etc.), estimo que es deber del querellante particular conocer las disposiciones procesales de carácter público $^{11}$ (imperativas) que regulan su intervención, en el marco de la garantía sinalagmática del debido proceso, tanto para él como para su contraparte. Una de esas reglas de intervención procesal es la contenida en el art. 110 del CPP 2004:

Se considerará tácito el desistimiento cuando el querellante particular no concurra sin justa causa a las audiencias correspondientes, a prestar su declaración o cuando no presente sus conclusiones al final de la audiencia. En los casos de incomparecencia, la justa causa deberá acreditarse, de ser posible, antes del inicio de la diligencia o, en caso contrario, dentro de las cuarenta y ocho horas siguientes a la fecha fijada para aquella.

En tal sentido, para que el proceso penal continúe y se pueda acceder al expreso pedido de reprogramación de la audiencia, el querellante particular debe acreditar, antes de la audiencia para la que fue correctamente citado y notificado, la justa causa de su inasistencia o hacerlo "dentro de las cuarenta y ocho horas siguientes a la fecha fijada para aquella". Si ninguna de esas opciones es ejercida por el querellante particular, corresponde declarar -

${ }_{10}$ Así lo establece el propio CPP 2004 al prescribir en el primer párrafo de su art. 483 que “La persona ofendida por una falta puede denunciar su comisión ante la Policía o dirigirse directamente al Juez comunicando el hecho, constituyéndose en querellante particular". Esto comporta apreciar que en el proceso penal por falta no interviene el representante de la sociedad, esto es el Fiscal, debido a que el interés lesionado no tiene, cuantitativamente, la misma entidad que aquella determinada por la lesión típica de un delito. Correlativamente, el propio Código Procesal Penal zanja la naturaleza del proceso penal por faltas al establecer que la persona ofendida que denuncia se constituye, per se, en querellante particular.

11 El derecho procesal es una expresión del derecho público, pues su naturaleza es pública. Sobre el particular, MONROY $(1996,54)$ puntualiza: "Siendo la función jurisdiccional una actividad especializada, única, irrenunciable y exclusiva del Estado, la regulación de su estructura, funcionamiento y métodos supone la existencia de normas cuya naturaleza es de derecho público (...)". 
Mario Lohonel Abanto Quevedo - Formas de culminación del Proceso Penal por falta.

Una propuesta de integración normativa

de oficio- el desistimiento tácito de la acción penal ${ }^{12} \mathrm{y}$, por consiguiente, el archivo definitivo del caso además de la anulación de los antecedentes policiales generados contra el procesado (si la denuncia se presentó ante esa dependencia).

Ya que las disposiciones procesales tienen carácter imperativo, pues vinculan a las partes con el poder estatal y este a su vez se legitima en tanto cumpla los estándares de eficacia, celeridad ${ }^{13}$, seguridad jurídica y respeto por las libertades individuales, ante el ejercicio doble de la opción omisiva del querellante particular (no asistir a la audiencia y luego no justificar oportunamente dicha inasistencia) debe aplicarse la consecuencia prevista en el citado art. 110 del CPP 2004.

\section{CONCILIACIÓN}

En el proceso penal por falta se ha establecido que la conciliación o la celebración de un acuerdo es la primera alternativa que debe intentarse en la audiencia (SÁNCHEZ VELARDE 2009, 403) para componer el conflicto entre las partes (art. 484.3 del CPP 2004). Esto relieva la importancia de la conciliación y concuerda con un fin axiológico (fin abstracto) del proceso, reconocido en el ya citado art. III del TP TUO CPC 1993, que es lograr la paz social en justicia ${ }^{14}$. Precisamente por esto es que el Juez de Paz Letrado y el Juez de Paz (Ley n. ${ }^{\circ}$ 29824) son competentes para conocer el proceso penal por falta ${ }^{15}$.

Siendo el de falta un proceso judicial que se inicia a instancia de la parte agraviada (en virtud al principio de autonomía de la voluntad) y que puede concluir por desistimiento si esta lo desea, la conciliación es posible sobre la base del mismo principio. La conciliación es una institución consensual y

\footnotetext{
12 A favor, MAchuca (Faltas contra la integridad física y el patrimonio 2011, 87)

13 SÁNCHEZ $(2009,28)$ opina: "la reforma implica cambio de actitud, mayor dinamismo, celeridad, observancia al debido proceso y a las normas de procedimiento, respeto a las autoridades judiciales y a sus decisiones".

14 Pese a esto, bajo las reglas del Código de Procedimientos Penales no era posible la conciliación intraproceso en faltas. MACHUCA $(2011,79)$ proporciona un buen ejemplo de lo perjudicial que esto era en casos como los de lesiones agravadas por violencia intrafamiliar.

15 Esto explica también la pérdida de competencia del Juez de Paz Letrado o de Paz para conocer un caso de lesión (dolosa o culposa) como falta (al margen del resultado de la evaluación médico legal) cuando "concurran circunstancias o medios que den gravedad al hecho, en cuyo caso será considerado como delito" (art. 441 del CP 1991). Tal caso no es uno en el que un Juez de Paz Letrado o de Paz pueda siquiera tentar una conciliación para restituir, precisamente, la paz perturbada. El interés lesionado va más allá de la exclusiva titularidad del agraviado. La gravedad del caso lesiona, en abstracto, el interés público. Al respecto, véanse las resoluciones emitidas en los expedientes n. ${ }^{\text {s }}$ 00228-2012-0-0601-JP-PE-04-Cajamarca, 00389-2011-0-0601-JP-PE04-Cajamarca (lesión dolosa) y 00368-2012-0-0601-JP-PE-04-Cajamarca (lesión culposa).
} 
Mario Lohonel Abanto Quevedo - Formas de culminación del Proceso Penal por falta.

Una propuesta de integración normativa

su aplicación es fomentada por el CPP 2004 a través del Juez ${ }^{16}$ (art. 463.3): "Instalada la audiencia se instará a las partes, en sesión privada, a que concilien y logren un acuerdo". Ya que predomina el interés particular, el Juez expresa el interés nacional en la "institucionalización y desarrollo de la conciliación como mecanismo alternativo de solución de conflictos" (Ley n. ${ }^{\circ}$ 26872, art. 1).

El rol facilitador del Juez para lograr la conciliación ${ }^{17}$ o el acuerdo, se concreta al promover el proceso de comunicación entre las partes y, eventualmente, proponer fórmulas conciliatorias no obligatorias (art. 20, Ley n. ${ }^{\circ}$ 26872). Así, el Juez propicia una cultura de paz siguiendo los principios éticos de equidad, veracidad, buena fe, confidencialidad, imparcialidad, neutralidad, legalidad, celeridad y economía (art. 2, Ley n. ${ }^{\circ}$ 26872). Esto se relaciona con la competencia del Juez (de Paz Letrado y de Paz) para los casos de falta que, por definición, no son graves y en los que el restablecimiento de la paz es posible (ver nota al pie 15).

Sin embargo, es difícil que las partes logren conciliar. En la experiencia judicial acumulada desde 2011, hemos advertido que las personas que son parte de un proceso penal por falta previamente han tenido un conflicto jurígeno (lesiones, maltrato, daños, hurto, etc.) que las indispone a conciliar. Esto es así pues su raciocinio está obnubilado por la molestia generada y la indisposición para el diálogo inteligente. Por eso, concurren a la audiencia buscando se imponga una sanción o para librarse de ella. No asisten con la intención de hacer prevalecer sus intereses, reconocer su responsabilidad o prevenir la reiteración de la falta.

No obstante, con la explicación que debe hacer el Juez y la mediación de los abogados, en la audiencia que no concluye por desistimiento expreso ni por sentencia, es posible que se produzca: 1) la conciliación pura, 2) la conciliación civil o acuerdo reparatorio (transacción), o 3) la conciliación mixta, que incluye una conciliación pura y la civil (acuerdo reparatorio). Lo importante es apreciar que en cualquiera de estos escenarios, el reconocimiento de la responsabilidad del procesado debe ser expreso. Si no lo es, pero ambas partes están dispuestas a conciliar, se debe explicar al procesado que su

\footnotetext{
16 "De acuerdo con los artículos 64 y 185 inciso 1) de la Ley Orgánica del Poder Judicial, el juez de paz (esencialmente juez de conciliación) señala como facultad de los magistrados: "propiciar la conciliación" (MACHUCA FUENTES 2011, 64).

17 García-Pablos de Molina $(2006,374)$ considera a la conciliación como una manifestación de la tendencia privatizadora del sistema penal. Dice de ella que "conciliación y mediación parecen fórmulas idóneas y eficaces, porque el enjuiciamiento convencional y la propia pena producen efectos nocivos irreparables elevando a cotas preocupantes el coste social de la intervención penal clásica".
} 
Mario Lohonel Abanto Quevedo - Formas de culminación del Proceso Penal por falta.

Una propuesta de integración normativa

predisposición a conciliar implica tácitamente la asunción de responsabilidad (penal y civil) por el hecho que el querellante particular le ha atribuido.

El Juez debe valorar esta circunstancia en el momento oportuno, porque a pesar de manifestar ambas partes su deseo de conciliar, finalmente es posible que la conciliación se frustre. Esto ocurre generalmente en los casos de la conciliación que hemos denominado como civil y también en la mixta. El motivo es el desacuerdo en el monto a pagar como parte del acuerdo reparatorio. Esto también lo advierte MACHUCA $(2011,92)$.

El art. 484.2 del CPP 2004 prescribe que producida la conciliación o acuerdo, éste se homologará, concluyendo las actuaciones, pero si fracasa, debe proseguir la audiencia. El Juez debe verificar que la conciliación entre las partes no afecte derechos indisponibles y se refiera a los puntos objeto del conflicto. De conformidad con los arts. 328 y 329 del TUO CPC 1993, de aplicación supletoria al proceso penal, la conciliación surte el mismo efecto que la sentencia judicial, por lo que tiene la autoridad de cosa juzgada, siendo instrumento pleno para el ejercicio de los derechos allí contenidos. Queda para la discusión si es que esta conciliación puede servir también para valorar la reincidencia en faltas, teniendo en cuenta que implica la aceptación de responsabilidad por el hecho denunciado, pero no es en estricto una sentencia condenatoria.

Por último, conviene -por economía procesal- declarar consentida en el mismo acto de audiencia, la resolución que declara la homologación de la conciliación y el acuerdo reparatorio.

\subsection{Conciliación pura}

La conciliación que denominamos pura es aquella que se produce por voluntad de la persona agraviada, que en el acto de audiencia perdona el agravio causado por la falta. Este es pues, el elemento esencial de esta conciliación. Por tal característica esta conciliación se diferencia del desistimiento, ya que precisa del reconocimiento de la responsabilidad del procesado y de la renuncia a la reparación civil. Otra variante implica requerir además el ofrecimiento de disculpas al querellante particular. Incluso, es posible que ambas partes o una de ellas, soliciten al Juez la imposición temporal de reglas de conducta a las que voluntariamente la contraparte del querellante particular se somete, de acuerdo a la naturaleza del conflicto que las enfrentó (útil para efectivizar el fin preventivo del art. I del TP CP 1991, como medio protector de la persona humana y de la sociedad). 
Mario Lohonel Abanto Quevedo - Formas de culminación del Proceso Penal por falta.

Una propuesta de integración normativa

El efecto de la conciliación pura sobre la vigencia de la acción penal es claro: ya no se pronuncia la pena. Al renunciar expresamente al derecho indemnizatorio, tampoco se estima la reparación civil. La conclusión del proceso, con la consiguiente cancelación de antecedentes policiales y el archivo definitivo, es la consecuencia legal de esta opción.

\subsection{Conciliación civil o acuerdo reparatorio}

La conciliación que denominamos civil (acuerdo reparatorio o transacción) es aquella que se propicia por voluntad de la persona agraviada, que en el acto de audiencia reclama únicamente la indemnización como condición para desistir de la pretensión penal. No perdona ni exige el ofrecimiento de disculpas. Tal es su nota característica. Implica, como en cualquier clase de conciliación, la aceptación del procesado y la admisión de su responsabilidad.

Su efecto sobre la acción penal es idéntico al caso anterior, pues tampoco se pronuncia la sentencia condenatoria, pero sí se consigna el reconocimiento de responsabilidad y el compromiso indemnizatorio. El pago puede realizarse en efectivo en el mismo acto de audiencia o mediante depósito judicial administrativo. En este último caso se suele consignar, como parte del acuerdo, el establecimiento de fechas de pago y cuotas. Finalmente, es posible el establecimiento de reglas de conducta según la naturaleza del caso, a pedido de una o ambas partes, pero siempre con su aceptación y conformidad.

\subsection{Conciliación mixta}

La conciliación mixta es aquella en la que se combinan las dos modalidades previas. El agraviado perdona y exige la indemnización, como condiciones para disponer de la pretensión penal; en tanto que el procesado reconoce su responsabilidad y se compromete a prestar la reparación. Las variantes ya explicadas también son admisibles: el requerimiento para ofrecer disculpas y el pedido para la imposición temporal de reglas de conducta (recomendamos que sea por un año, en referencia con el término mínimo de la reserva del fallo condenatorio en el que también se imponen reglas de conducta y para inhibir la reincidencia). 
Mario Lohonel Abanto Quevedo - Formas de culminación del Proceso Penal por falta.

Una propuesta de integración normativa

\section{SENTENCIA QUE SE PRONUNCIA POR LA RESPONSABILIDAD PENAL}

Cuando el proceso penal por falta no termina ni por desistimiento ni por conciliación, solo es posible su conclusión mediante sentencia. Esta sentencia puede emitirse en caso se produzca la terminación anticipada de la audiencia por aceptación de la imputación y de la responsabilidad derivada (penal y civil) o como resultado de la audiencia y la valoración de los elementos probatorios y la actuación de medios de prueba.

Si bien el art. 484.6 del CPP 2004 autoriza a dictar sentencia en el acto de audiencia o dentro del tercer día de su culminación sin más dilación, recomendamos optar siempre por la primera opción. Esta propuesta se sustenta en que es requisito previo a la realización de la audiencia haber estudiado bien el expediente y, ya en ella, haber valorado los elementos de prueba presentados y los medios de prueba actuados; aprovechar el principio de inmediación ${ }^{18}$, la transparencia que brinda la publicidad del acto de audiencia y la economía procesal.

La sentencia que se pronuncia afirmando la responsabilidad penal puede hacerlo condenando, reservando el fallo condenatorio o decidiendo la exención de pena. Solo en el primer caso, la sentencia sirve para la consideración de la reincidencia en faltas dolosas, reguladas en los arts. 441 y 444 del CP 1991, en concordancia con el primer párrafo del art. 46-B del mismo Código.

\subsection{Sentencia condenatoria}

El CP 1991 establece como bases de punibilidad sancionar delitos y faltas, esto es, comportamientos antijurídicos, dolosos o culposos, que realizados por comisión u omisión, tienen asignados una sanción penal con anticipación a su realización.

La sentencia condenatoria presupone que durante la investigación y la audiencia del caso se ha acreditado la responsabilidad penal. Esto implica declarar probado el resultado típico, su curso causal y su atribución válida al procesado. Significa pues, afirmar una conducta antijurídica y culpable con total convencimiento.

\footnotetext{
18 SAN MARTín CASTRO $(2003,1263)$ relieva la importancia de la inmediación en la audiencia dirigida por el Juez en un caso de falta y lo hace citando a Víctor MORENO CATENA: “...las actuaciones que se exigen en este tipo de proceso (...) están presididas y dirigidas por el juez".
} 
Mario Lohonel Abanto Quevedo - Formas de culminación del Proceso Penal por falta.

Una propuesta de integración normativa

En cuanto a la responsabilidad penal, debe haberse acreditado que el procesado pudo actuar conforme a derecho en la situación concreta en la que se encontró y no lo hizo por propia determinación. Acreditada la responsabilidad penal es menester determinar la pena a imponerse y el monto de reparación civil necesario. Sobre el primer punto, debe recurrirse al examen de los elementos del art. 46 del CP 1991 (aplicable en virtud a la prescripción del art. 440 de la misma disposición legal). Para los casos de faltas, sin pretensión de exclusividad, se tornan especialmente importantes: i) la naturaleza de la acción; ii) la importancia de los deberes infringidos; iii) la extensión del daño o peligro causados; iv) las circunstancias de tiempo, lugar, modo y ocasión; y v) la edad, educación, situación económica y medio social del procesado.

Sobre la responsabilidad civil, se deberá fijar un monto por reparación a favor del agraviado, esto es, una indemnización por los daños y perjuicios causados, tal como prescriben los arts. 92 y 93 del CP 1991. Para hacerlo, debe valorarse la diligente actividad probatoria del agraviado. Justificar su pretensión resarcitoria es una obligación que este debe cumplir antes de la calificación del caso, bajo sanción de inadmisibilidad de su denuncia, según el art. 108 del CPP 2004. El Juez no puede suplir este deber pero sí debe aplicar el criterio de proporcionalidad para fijar un monto prudente ${ }^{19}$ por reparación civil, teniendo en cuenta el daño causado pero no las posibilidades económicas del procesado (CHINCHAy CASTILLO 2007, 223). Esto es así porque nada tiene que ver el daño reparable con las posibilidades económicas del procesado. Si bien a esta interpretación puede oponerse que en función a la ocupación del procesado y su carga familiar, sobre las que se le pregunta en el acto de audiencia, se busca que el monto fijado sea posible de pagar, esto afecta al agraviado pues la cantidad obtenida no se aproximaría al concepto de reparación civil ${ }^{20}$.

\subsection{Sentencia con reserva de fallo condenatorio}

La sentencia en la que se opta por aplicar la reserva de fallo condenatorio concreta una opción de política criminal del Juez. Esta potestad se ejerce en

\footnotetext{
${ }_{19}$ Es posible trasladar el conocimiento privado del Juez (máximas de experiencia o sentido común) al ámbito de la prueba, lo cual está permitido en nuestro sistema jurídico, de acuerdo al art. 281 del TUO CPC 1993: "El razonamiento lógico-crítico del Juez, basado en reglas de experiencia o en sus conocimientos y a partir del presupuesto debidamente acreditado en el proceso, contribuye a formar convicción respecto al hecho o hechos investigados". Según Stein $(1999,27)$, estas máximas de experiencia son definiciones o juicios hipotéticos o de contenido general, desligados de los hechos concretos que se juzgan en el proceso, procedentes de la experiencia, pero independientes de los casos particulares de cuya observación se han inducido, y que por encima de esos casos, pretenden tener validez para otros nuevos. Así, este conocimiento puede integrar el juicio de proporcionalidad para establecer el monto por reparación civil.

20 Propone CHINCHAY CASTILLO (ibíd.) que "fijar un monto verdadero puede ayudar a la víctima para otros efectos: deducciones tributarias, ajustes de indemnización con su compañía de seguros, eventualmente tener la expectativa de cobrar más adelante, si la situación económica del condenado mejora".
} 
Mario Lohonel Abanto Quevedo - Formas de culminación del Proceso Penal por falta.

Una propuesta de integración normativa

interés de ambas partes, para prevenir la reiteración de la falta a través del establecimiento de reglas de conducta, determinadas por la clase de falta cometida y para lograr la reparación del daño causado. El art. 62 del CP 1991 establece:

El Juez podrá disponer la reserva del fallo condenatorio cuando la naturaleza, modalidad del hecho punible y personalidad del agente, hagan prever que esta medida le impedirá cometer un nuevo delito. La reserva será dispuesta:... inciso 2) Cuando la pena a imponerse no supere las noventa jornadas de prestación de servicios a la comunidad o de limitación de días libres.

De acuerdo a esta disposición legal, habrá que examinar en el caso concreto: 1) si conviene reservar el extremo condenatorio (evaluación subjetiva) y 2) si luego de individualizar la pena concreta, esta se ubica dentro de los márgenes permisibles (evaluación objetiva). La conducta del procesado (si acudió al llamado jurisdiccional, ejerció su defensa con lealtad y honestidad) así como su personalidad (su educación, reconoció su responsabilidad y estuvo dispuesto a conciliar) deben ser valoradas por el Juez para prever si es una persona no propensa a cometer actos ilícitos. Si este juicio es afirmativo, se puede asumir que la reserva del fallo condenatorio y sus reglas de conducta le impedirán cometer una nueva falta, al incidir en su futura determinación personal. Esta medida le brinda garantía al agraviado en el cumplimiento de las reglas de conducta, pues estas son impuestas por un Juez en el ejercicio regular de sus funciones. Si son desobedecidas, ante la nueva denuncia podrán remitirse copias certificadas del expediente archivado al Ministerio Público, para la investigación por el delito de desobediencia a la autoridad (art. 368 CP 1991).

Aplicar la reserva del fallo condenatorio implica declarar la culpabilidad del procesado, pero sin establecer la pena momentáneamente. Sin embargo, esta reserva se limita a no incorporar la pena en la parte resolutiva (ejecutiva) de la sentencia, pero no elimina el deber judicial de determinarla por la virtualidad de su imposición futura. La determinación de la pena concreta obedece a los parámetros ya explicados en el caso de la sentencia condenatoria. Sugerimos conveniente consignar, en un párrafo considerativo de la sentencia, la pena concreta que se hubiera impuesto. Así debe hacerse en virtud de los principios de inmediación y dirección del proceso penal. En caso deba revocarse la reserva e imponerse la pena, incluso cuando deba hacerlo un Juez distinto al que sentenció, se optimizan esfuerzo y tiempo.

La ejecución del extremo punitivo determinado se reserva y se condiciona su extinción o imposición a la culminación exitosa -o no- de un periodo de 
Mario Lohonel Abanto Quevedo - Formas de culminación del Proceso Penal por falta.

Una propuesta de integración normativa

prueba, dentro del cual el procesado deberá abstenerse de cometer nueva falta y cumplir las reglas de conducta que se le señalen.

Por último, la reserva de fallo condenatorio no implica eludir la determinación de la responsabilidad civil, según se explicó previamente.

\subsection{Sentencia de exención de pena}

La exención de pena no es una alternativa frecuentemente empleada por los jueces con competencia penal ${ }^{21}$. El art. 68 del CP 1991 prescribe:

El juez puede eximir de sanción en los casos en que el delito esté previsto en la ley con pena privativa de libertad no mayor de dos años o con pena limitativa de derechos o con multa si la responsabilidad del agente fuere mínima.

Esta es otra facultad jurisdiccional cuyo fundamento reside en la política criminal. De acuerdo a la disposición legal transcrita, habrá que verificar si en el caso concreto se cumplen los dos supuestos exigidos y concurrentes. Si es así, será posible declarar la exención de la pena en interés de la prevención especial positiva (Prado Saldarriaga 2000, 213). Esta conclusión se facilita si el procesado se ha sometido voluntariamente al proceso, si ha reconocido su responsabilidad o si ha estado dispuesto a conciliar. Estos signos implican la comprensión de la ilicitud e impropiedad de su conducta. El perdón judicial ${ }^{22}$, cuya excepcionalidad le debe ser explicada en la audiencia, incidirá en su determinación personal para no cometer una nueva falta.

Al aplicar la exención de pena, implícitamente se declara la culpabilidad del procesado, pero sin emitir la consiguiente condena, la pena ni la reparación civil (que no se calcula al no haberse determinado pena alguna, según el art. 92 del CP 1991) ${ }^{23}$. Considero que el perdón judicial penal debe ser completo, tanto respecto a la pena como a la reparación civil. A salvo queda el derecho de la parte agraviada sobre este aspecto, pues la sentencia que declara la

\footnotetext{
${ }^{21}$ Hemos encontrado escasos ejemplos: consulta 1544-95-B-Lambayeque, Exp. 2672-2003-HC/TC, Exp. 830-91-Huánuco (Ejecutoria Suprema), Exp. 3361-93-B-Lima, Exp. 598-2010-0-0601-JP-PE-04-Cajamarca y Exp. 730-2010-0-0601-JP-PE-04-Cajamarca.

22 Resolución n. ${ }^{\circ} 29$ del 20 de noviembre de 2009, Inc. 03-2009-"B", Primera Sala Penal Especial (C.II-14.a) de la Corte Superior de Justicia de Lima. Disponible en: http://historico.pj.gob.pe/cortesuprema/documentos/ Inc. \%2003-09-B.pdf (consultada el 12 de julio de 2012)

23 En contra de esta posición, Prado Saldarriaga (2000, 214) sostiene: “Si bien el Código Penal (...) no alude a los efectos de la exención de pena sobre la reparación civil, resulta fácil inferir que su concesión no excluye el señalamiento de responsabilidades indemnizatorias, puesto que éstas son exigibles desde la producción de un hecho antijurídico. Por tanto, el Juez debe fijar en la sentencia la reparación civil que corresponda".
} 
Mario Lohonel Abanto Quevedo - Formas de culminación del Proceso Penal por falta.

Una propuesta de integración normativa

culpabilidad pero exime de pena, le habilita la vía civil para su reclamo (en concordancia con el art. 12.3 del CPP 2004).

Esta exención de pena no extingue su ejecución, como podría asumirse del art. 85.3 del CP 1991, pues la pena nunca se determinó ni se impuso y aun menos empezó a ejecutarse (presupuesto lógico para la extinción de su ejecución). Dicha previsión del CP 1991 se refiere, por ejemplo, a la exención de pena por vínculo familiar en caso de encubrimiento real.

Por último, al decidir el Juez aplicar la exención de pena, no se registran antecedentes penales. Nuevamente, puede discutirse si una sentencia de este tipo puede valorarse para la consideración de la reincidencia.

\section{SENTENCIA QUE SE PRONUNCIA POR LA IRRESPONSABILIDAD PENAL}

De acuerdo al art. 43 ab initio de la CP 1993: "La República del Perú es democrática, social, independiente y soberana". Por el componente social se busca el bienestar de la población en general, tutelando el interés colectivo. Por el componente democrático, fiel a su origen liberal, en el caso específico se anteponen los derechos individuales frente a la pretensión colectiva, haciendo uso del derecho.

Es el derecho el ambiente adecuado para amalgamar estas dos pretensiones aparentemente excluyentes. Una condena se produce en interés social cuando la culpabilidad individual ha sido demostrada. La absolución se produce en interés individual, cuando no ha sido probada la culpabilidad, ya sea por insuficiencia probatoria o por existir una duda razonable respecto a ella, pero también se produce cuando la inocencia ha quedado evidenciada en forma meridiana ${ }^{24}$.

En el marco del debido proceso debe probarse la comisión del hecho ilícito y la responsabilidad del autor mediante elementos de prueba fehacientes e idóneos. En ese orden de ideas, el juzgamiento se produce sobre la base de los elementos probatorios obtenidos en la investigación preliminar, siendo el acto oral la fase culminante de la necesaria y rigurosa actividad probatoria, practicada bajo la influencia del principio de contradicción. Un fallo condenatorio exige del juzgador la certeza de la responsabilidad penal del

\footnotetext{
${ }^{24}$ Sentencia de la Primera Sala Especializada Penal de la Corte Superior de Justicia de Cajamarca, proceso penal n. ${ }^{\circ}$ 334-95-P (Tercer Juzgado Especializado Penal), emitida el 14 de octubre de 2008. Novena consideración.
} 
Mario Lohonel Abanto Quevedo - Formas de culminación del Proceso Penal por falta.

Una propuesta de integración normativa

procesado, que sólo puede ser obtenida a partir de una actividad probatoria contundente que permita generar tal convicción de culpabilidad. De no existir suficiencia de pruebas debe prevalecer la garantía constitucional del principio de presunción de inocencia. ${ }^{25}$ En caso de contar con elementos probatorios ya sea para absolver o para condenar, debe aplicarse el principio in dubio pro $r e o^{26}$, siendo preferible absolver al procesado antes que condenarle si subsiste duda acerca de su responsabilidad penal.

\section{ABANDONO DEL PROCESO}

Al referirnos al desistimiento tácito sustentamos que el querellante particular debe conocer las disposiciones procesales de carácter público que regulan su intervención procesal. Otra de esas reglas es la instituida en el art. 464.1 del CPP 2004: "La inactividad procesal durante tres meses, produce el abandono del proceso, que será declarado de oficio".

Si el querellante particular conoce de la sustanciación del proceso penal por falta que instó y voluntariamente no concurre a las citaciones judiciales ni se

25 Ibíd. undécima consideración: “La presunción de inocencia es un derecho fundamental, recogido en la Declaración Universal de los Derechos Humanos, también en los tratados internacionales sobre esta materia suscritos y ratificados por el Estado peruano y prescrito en la Constitución Política vigente en el literal "e" del inciso veinticuatro de su segundo artículo. De acuerdo a este principio, toda persona a la que se le ha imputado la comisión de un hecho punible es considerada inocente y debe ser tratada como tal mientras no se demuestre lo contrario declarándose su responsabilidad penal mediante sentencia firme debidamente motivada. Para estos efectos, se requiere de una suficiente actividad probatoria de cargo, obtenida y actuada con las debidas garantías procesales. Este derecho apareja la consecuencia lógica de que en caso de duda sobre la responsabilidad penal, debe resolverse a favor del imputado, absolviéndole de los cargos formulados en su contra. Si se tiene en cuenta que la presunción de inocencia se materializa concretamente en dos garantías, a saber, regla probatoria (...) y la regla de tratamiento o de juicio del imputado, es por cuenta de la segunda que este Colegiado asume la acusación como hipótesis que sólo puede llevarle a la afirmación de culpabilidad a través de la comprobación cuidadosa del fundamento probatorio de todos y cada uno de los elementos de la imputación, según ha resultado del juicio. Se lesiona este principio cuando se condena al imputado y no existen elementos probatorios válidos que acrediten su responsabilidad penal o cuyo mérito probatorio es insuficiente para desvirtuar la presunción de inocencia que le asiste... Sobre esto, el artículo octavo, segundo numeral de la Convención Americana de Derechos Humanos prescribe que "una persona no puede ser condenada mientras no exista prueba plena de su responsabilidad penal. Si obra contra ella prueba incompleta o insuficiente, no es procedente para condenarla, sino para absolverla...".

26 Ibíd. duodécima consideración: "Respecto al principio in dubio pro reo, este se desprende interpretativamente del inciso once del artículo ciento treinta y nueve de la Constitución Política y es un límite al poder punitivo del Estado, ya que ante un supuesto de duda (o conflicto de leyes), se impone al juez la obligación de elegir la opción que más favorezca al procesado. De otra manera no habría correlato con el fin de seguridad exigido en todo Estado social y democrático de Derecho, en el que la defensa de la dignidad de la persona humana, de su libertad y la consiguiente protección de las garantías ciudadanas, son pilares fundamentales de la sociedad. La razón que legitima a este principio es la de garantizar el deber del Estado de probar la plena culpabilidad del procesado, pues es su inocencia la que se presume y es ésta la que debe desvirtuarse en el proceso penal probando la hipótesis de culpabilidad del Ministerio Público... Por ello, ya que en este proceso penal la culpabilidad no se ha acreditado, la absolución es el único camino legítimo a fin de preservar la libertad individual en correlato con la defensa constitucional de la persona (in oscuro, libertatem praevalere)." 
Mario Lohonel Abanto Quevedo - Formas de culminación del Proceso Penal por falta.

Una propuesta de integración normativa

acerca al Juzgado de Paz Letrado o al de Paz para averiguar acerca del estado procesal del caso, es responsable de su inactividad. En el supuesto planteado le sería imputable al querellante particular la situación de inactividad procesal en la que se encontraría el expediente respecto de sus pretensiones. Declarado de oficio el abandono del proceso, habrá que notificar esta resolución, que puede ser apelada y en caso de confirmarse, provocará el archivo definitivo del caso.

Puede presentarse un caso especial de abandono, regulado en el art. 465 del CPP 2004, referido a la muerte o subsecuente incapacidad del querellante particular. Cuando alguna de estas dos situaciones se produce, puede que el Juez no se entere y el abandono será declarado de oficio luego de los tres meses posteriores al último acto procesal impulsado por el querellante particular. Pero puede suceder también que el Juez sea noticiado por el procesado de esta nueva circunstancia, en cuyo caso, se declarará el abandono después de los treinta días siguientes de la muerte o incapacidad, si es que ninguno de los herederos del querellante particular se ha apersonado para asumir ese rol.

\section{PRESCRIPCIÓN DE LA ACCIÓN PENAL}

El 16 de noviembre de 2010, los Jueces de las dos Salas Penales de la Corte Suprema, al tratar la figura de la reincidencia en faltas, se ocuparon también de los plazos de prescripción de la pena para esta clase de ilícito penal, habiéndolo hecho antes respecto a los plazos de prescripción de la acción penal (fundamentos jurídicos 21 y 22 del Acuerdo Plenario n. ${ }^{\circ} 1-2010 / C J-$ 116).

De ese modo, leyendo completamente el acuerdo y nuevamente haciendo una interpretación integradora ${ }^{27}$, se pueden extraer cuatro normas jurídicas que abarcan todos los escenarios de prescripción para las faltas:

1) La acción penal y la pena prescriben -ordinariamente- al año cuando no hay reincidencia.

2) La acción penal y la pena prescriben -extraordinariamente- al año y medio cuando no hay reincidencia.

3) La acción penal y la pena prescriben -ordinariamente- a los dos años en caso de reincidencia.

4) La acción penal y la pena prescriben -extraordinariamente- a los tres años en caso de reincidencia.

\footnotetext{
27 Resolución del Cuarto Juzgado de Paz Letrado de la Corte Superior de Justicia de Cajamarca, proceso penal n. ${ }^{\circ}$ 00519-2010-0-0601-JP-PE-04, expedida el 27 de agosto de 2012.
} 
Mario Lohonel Abanto Quevedo - Formas de culminación del Proceso Penal por falta.

Una propuesta de integración normativa

Sobre el Acuerdo Plenario n. ${ }^{\circ} 1-2010 / C J-116$, que sustenta estas cuatro normas jurídicas, MACHUCA $(2011,26)$ opina:

“Esto no es una interpretación antojadiza de la norma pues no debe perderse de vista que la prescripción es una institución de naturaleza procesal inserta en el ordenamiento sustantivo y, por ende, no es perjudicial a las faltas el que se apliquen las reglas procesales que rigen para los delitos...".

Ya que la literalidad del CP 1991 establece en uno y dos años el plazo de prescripción para la acción penal y la pena en los casos de faltas (art. 440.5), es muy frecuente que entre la denuncia y su trámite previo a la audiencia, buena parte de ese tiempo ya haya transcurrido. Por eso, la opción interpretativa de los Jueces de la Corte Suprema de Justicia tiende a evitar la impunidad. También, con este Acuerdo Plenario se intenta (dado el carácter no vinculante de la doctrina legal) zanjar una discusión entre los jueces que, optando por una interpretación a favor del procesado, consideran que dicho plazo incluye al de la prescripción extraordinaria y aquellos otros que acogiendo esta variante, añaden la mitad del plazo, según sea el caso, para fijar el límite de vigencia de la acción penal y de la pena.

\section{CONCLUSIONES}

El Juez de Paz Letrado tiene el deber de impartir justicia penal por faltas a pesar de los vacíos regulatorios. Para hacerlo debe integrar las disposiciones que regulan tal proceso penal, las del proceso por querella y las del proceso común, interpretándolas sistemáticamente.

En esta tarea debe procurarse efectivizar la separación de los roles de acusar, investigar y juzgar, identificando a sus responsables y procurando que cumplan diligentemente tales roles.

El agraviado por un caso de falta puede denunciarlo ante la Policía o directamente ante el Juez, pero al hacerlo debe saber que su denuncia tiene que ser formal y completa, en los términos del art. 108 del CPP 2004, pues el incumplimiento de dichas exigencias implica la inadmisibilidad de su denuncia.

Luego, el agraviado, ya constituido en querellante particular, debe desempeñar con diligencia los derechos que le asisten, así como conocer sus limitaciones y responsabilidades. La carga de la prueba es su principal responsabilidad. 
Mario Lohonel Abanto Quevedo - Formas de culminación del Proceso Penal por falta.

Una propuesta de integración normativa

Las formas de conclusión del proceso penal por falta (desistimiento, conciliación, sentencia, abandono y prescripción) se sustentan en el CPP 2004 y en la actividad interpretativa de los Jueces, por lo que es de cargo de las partes y de sus abogados conocerlas.

El Juez debe priorizar y propiciar la conciliación como forma estelar de culminación del proceso penal por falta (cuando es posible), ya que contribuye al restablecimiento de la paz entre las partes, en concordancia con el fin abstracto del proceso y con la propia nomenclatura de su cargo.

Las formas especiales (desistimiento expreso y conciliación civil o transacción) para concluir el proceso penal por falta no se aplican en los casos donde el agraviado es la sociedad (faltas contra la tranquilidad o seguridad pública) (MACHUCA FUENTES 2011, 67).

El Juez es un actor principal de la política criminal nacional. Como tal, con base en su conocimiento criminológico, debe decidir la aplicación de la exención de pena cuando el caso cumpla con los dos requisitos concurrentes exigidos por el art. 68 del CP 1991. 
Mario Lohonel Abanto Quevedo - Formas de culminación del Proceso Penal por falta.

Una propuesta de integración normativa

\section{LISTA DE REFERENCIAS}

CHINChay CASTILlo, Alcides. "La víctima y su reparación en el proceso penal peruano». Diálogo con la jurisprudencia (Gaceta Jurídica), n 108 (Setiembre 2007): 215-223.

GÁlveZ Villegas, Tomás Aladino, William Rabanal Palacios, y Hamilton CAstro Trigoso. «El Código Procesal Penal. Comentarios descriptivos, explicativos y críticos». Lima: Jurista Editores EIRL, 2009.

GaRCíA-PABlos DE Molina, Antonio. "Conciliación y conformidad como manifestaciones de las tendencias privatizadoras del sistema penal». Estudios de Derecho Penal. Libro homenaje a Domingo GARCíA RADA (Adrus), 2006: 373406.

MACHUCA FUENTES, Carlos. "Faltas contra la integridad física y el patrimonio». Lima: Gaceta Jurídica, 2011.

Monroy GÁLveZ, Juan. «Introducción al Proceso Civil». Vol. I. Bogotá: Temis, 1996.

PRAdo SAlDARRIAGA, Víctor Roberto. «Las consecuencias jurídicas del delito en el Perú». Lima: Gaceta Jurídica, 2000.

SAN MARTín CASTRO, César Eugenio. «Derecho procesal penal». Vol. II. Lima: Grijley, 2003.

SÁNCheZ Velarde, Pablo Wilfredo. «El nuevo proceso penal». Lima: Idemsa, 2009.

STEIN, Friedrich. «El conocimiento privado del juez». Bogotá: Temis, 1999. 